\title{
Centimetre-scale spatial structure of estuarine in vivo fluorescence profiles
}

\author{
Raechel L. Waters*, James G. Mitchell \\ School of Biological Sciences, The Flinders University of South Australia, GPO Box 2100, Adelaide 5001, South Australia
}

\begin{abstract}
The spatial complexity of phytoplankton distributions at large (metre to kilometre) scales has long been recognised. Here we present evidence of structure identified in the spatial distributions of phytoplankton measured at decimetre and centimetre scales. To characterise the temporal and spatial variation in the structure of phytoplankton distributions, fractal analysis was applied to vertical in vivo fluorescence profiles sampled at $25 \mathrm{~cm}$ and $5 \mathrm{~cm}$ sampling intervals. At the decimetre scale, mean fractal dimensions of in vivo fluorescence profiles were highly variable and not statistically distinct from those of complementary temperature and salinity profiles, suggestive of similar structuring processes for both biological and physical distributions. Sampling at the centimetre scale resolved increased structural complexity in in vivo fluorescence distributions, including the presence of multiple scaling regions, indicative of multiple structuring mechanism, together with the presence of distinct changes in the vertical structure of distributions for profiles separated by a horizontal distance of $7 \mathrm{~cm}$. Shifts in centimetre-scale structural complexity were attributed to the behavioural reorganisation of cells due to a phototactic response to light and a gyrotactic or rheotactic response to localised shear. These results verify the importance of biological-physical structuring mechanisms down to the centimetre scale, where cell distributions and interactions hold significant ecological relevance.
\end{abstract}

KEY WORDS: In vivo fluorescence - Centimetre scale · Fractal dimension · Biological-physical coupling

Resale or republication not permitted without written consent of the publisher

\section{INTRODUCTION}

Patchy distributions of marine phytoplankton are documented over centimetres to hundreds of kilometres (Cassie 1963, Fasham 1978, Mackas et al. 1985). The quantification of the spatial structure of phytoplankton distributions has for the most part focused on empirical observations at scales of greater than $10 \mathrm{~m}$ to several $\mathrm{km}$, where variability in phytoplankton distributions were observed to be highly variable in both space and time, creating a continuum of structure over multiple-length scales (Platt 1972, Mackas et al. 1985). Analysis techniques employed to characterise large-scale phytoplankton distributions are therefore capable of resolving

*E-mail: raechel.waters@flinders.edu.au multiscale patterns (e.g. Platt \& Denman 1975, Strutton et al. 1996, Seuront et al. 1999). While the interpretation of spatial structure at scales greater than $10 \mathrm{~m}$ is important to the continuing investigation of biological-physical coupling mechanisms that occur at time scales of days to weeks (e.g. Denman 1994), we are becoming increasingly aware of the importance of processes operating at scales of millimetres to a metre, with time scales of seconds to minutes. It is at these scales where the interaction of turbulent motion, experienced as eddies ranging in size from millimetres to centimetres (Mitchell et al. 1985), and the organisation of populations directly affects the processes of nutrient uptake (e.g. Lazier \& Mann 1989, Karp-Boss et al. 1996, Pahlow et al. 1997, Blackburn et al. 1998), light harvesting (Kirk 1994), predator-prey encounter rates (e.g. Rothschild \& Os- 
borne 1988, Kiørboe 1997, Sundby 1997) and behaviour (e.g. Kessler 1986, Green \& Diez 1995, Kamykowski et al. 1997). In contrast to large-scale studies, there is limited information on the spatial organisation of phytoplankton at these ecologically relevant scales.

The standard assumption is that turbulence homogenises phytoplankton distributions at scales less than $1 \mathrm{~m}$ (Okubo 1980, Denman \& Powell 1984). The reality is that this scale may be structurally complex. The existence of variability in phytoplankton distributions at scales of tens of centimetres has been well documented in estuarine (McAlice 1970, Donaghay et al. 1992), coastal/fiordic (Bjørnsen \& Nielsen 1991, Tiselius et al. 1994, Montagnes et al. 1999) and open water (Derenbach 1979, Mitchell \& Fuhrman 1989, Owen 1989, Cowles et al. 1993) environments. Early attempts to quantify this microscale variability included the microscale variation (MSV) index developed by Owen (1989), which is a measure of the mean-square deviations, over the observed concentration about a mean gradient, for a linear series of measurements. While the MSV index does provide a quantified measure of spatial variation, it is limited to one length scale. A multiscale measure is needed that links sub- and supra-metre structure. Generally, microscale studies have employed a variety of linear bottle and syringetype samplers (McAlice 1970, Mitchell \& Fuhrman 1989, Owen 1989, Bjørnsen \& Nielsen 1991, Tiselius et al. 1994, Montagnes et al. 1999) resulting in data sets that are insufficient for the application of traditional multiscale analysis techniques (Chatfield 1989, recommends a sample size of $>1000$ for spectral analysis). Here we present a multiscale spatial quantification method, employing fractal geometry, which is not sensitive to small data sets, providing for the first time a quantification method that can be applied to a range of existing microscale data sets. Fractal geometry has increased in popularity in ecological studies (Frontier 1987, Palmer 1988, Sugihara \& May 1990) and has been successfully employed for the quantification of large-scale temporal and spatial distributions of phytoplankton (Seuront \& Lagadeuc 1997, 1998).

Fractal analysis identifies scale-dependent selfsimilarity (Mandelbrot 1977, 1983) in the data set, where self-similarity describes the repetition of pattern observed at one scale at smaller or larger scales (Peitgen et al. 1992). Here we use the term 'self-similarity' in a statistical sense, where scale dependence may not be immediately apparent but can be identified when variance comparisons are made between scales. The form of the observed scale dependence, which characterises the relationship between pattern and the scale of measurement, can then be characterised using the fractal dimension $\left(D_{\mathrm{F}}\right)$. Akin to spectral analysis, this is a power law function that describes the relation- ship between the descriptor and the scale on which it is measured, where the exponent of the power law is $D_{\mathrm{F}}$. In addition to providing information on how a quantity relates to the scale of measurement, $D_{\mathrm{F}}$ reveals the organisation of variability in space or time. For a linear series, if a descriptive variable increases (or decreases) consistently and uniformly as a function of scale (sampling interval), then the relationship is linear and the estimated $D_{\mathrm{F}}=1$. If, on the other hand, there is no selfsimilarity and therefore complete spatial-scale independence, expressed as no change in the descriptor with scale ('white noise'), then the distribution has a $D_{\mathrm{F}}=2$ (Burrough 1981). Distributions that approach $D_{\mathrm{F}}=2$ are dominated by short-range structuring processes, such that small-scale variability smooths out long-range effects, resulting in an even distribution of the variable and therefore weak spatial dependence. Conversely, for distributions with $D_{\mathrm{F}}$ values approaching 1 , long-range effects dominate, resulting in increased spatial complexity and strong-scale dependence (Burrough 1983).

Here we apply fractal analysis to identify scaling behaviour in vertical series of in vivo fluorescence sampled at 25 and $5 \mathrm{~cm}$ intervals in a low energy estuarine environment. At the decimetre scale the presence of structure is variable and closely linked to the spatial organisation of physical variables, suggestive of similar structuring processes. At the centimetre scale, scaling dependence is a consistent feature, indicative of increased spatial organisation at these ecologically relevant length scales. In addition, the complexity of structure is increased, the details of which may provide insight into the role of behaviour in the organisation of cells in low energy environments.

\section{MATERIALS AND METHODS}

Sampling procedures. Samples were obtained from the Port River Estuary, South Australia $\left(34^{\circ} 44^{\prime} \mathrm{S}\right.$, $138^{\circ} 32^{\prime} \mathrm{W}$ ). It is a tidally flushed, 4 to $15 \mathrm{~m}$ deep, working port with a mean salinity of approximately $35 \%$. The major source of freshwater into the system is a sewage treatment works; this input occurs as an intense pulse during periods of increased rainfall or sewage use. The estuary is flooded tidally from the Gulf St. Vincent. The shape and orientation of the Gulf St. Vincent produce approximately equal solar and lunar tide amplitudes. Fortnightly, these tides are in antiphase during the neap period, producing minimal vertical water movement. To determine the effects of minimal tidal mixing on phytoplankton distributions, samples were taken over 3 consecutive $24 \mathrm{~h}$ periods, in April 1997, to coincide with pre-neap (April 15/16), neap (April 17/18) and post-neap (April 19/20) condi- 
tions. Taxonomic data were collected during the study period and were provided as comparative data by T. Ault (pers. comm.).

Decimetre-scale profiles. Water samples were collected at $25 \mathrm{~cm}$ intervals (to a maximum depth of $4 \mathrm{~m}$ ) with a submersible pump (tube inner diameter [i.d.] = $11.5 \mathrm{~mm})$. In vivo fluorescence was determined from $15 \mathrm{ml}$ dark-adapted water samples with a Turner Designs AU-10 field fluorometer. Physical variables (temperature, salinity and photosynthetically active radiation $[\mathrm{PAR}]$ ) were measured in situ, simultaneously with the collection of pump samples, by means of a YSI mini sonde (YSI 85) with an attached LICOR (LI192SA) light meter. Sigma-t values were calculated from the United Nations Educational, Scientific and Cultural Organization (UNESCO) equation of state (Millero et al. 1980, Fofonoff \& Millard 1983). Profiles were measured for each variable (in vivo fluorescence, temperature and salinity) every $3 \mathrm{~h}$ in each $24 \mathrm{~h}$ period, starting at 09:00 $\mathrm{h}$, resulting in a total of 24 profiles of each variable for the whole study period.

Centimetre-scale profiles. In addition to the pump profiles, water samples (for in vivo fluorescence determination) were taken with 2 pneumatically operated syringe sampling devices (adapted from the designs of Baker et al. 1985). The first consisted of a linear series of 57 syringes $(20 \mathrm{ml}$ ) spaced $5 \mathrm{~cm}$ apart, resulting in a total length of $3 \mathrm{~m}$. The second syringe sampler was constructed in the same manner as the linear sampler but consisted of an array of $3 \times 19$ syringes organised into 3 linear series, $1 \mathrm{~m}$ in length, separated by $7 \mathrm{~cm}$. These 2 devices are identified as 'linear' and 'array' samplers, respectively. In vivo fluorescence of collected water samples was determined as described above. Two samples were taken with each of the syringe devices during each $24 \mathrm{~h}$ period, with array samples positioned to coincide with the fluorescence maximum (as determined from pump samples), resulting in 6 linear and $18(6 \times 3)$ array profiles over the entire study period. Multiple-point measurements of physical variables to complement centimetre-scale biological data were not available.

Data analysis. To determine the structure of phytoplankton and physical variable distributions, $D_{\text {F }}$ values were estimated for all profiles. The methodology employed is described in detail by Seuront \& Lagadeuc (1997, 1998). The method was originally described by Burrough $(1981,1983)$ and is based on geostatistic and regionalised (autocorrelated) variable (RV) theory (Journel \& Huijbregts 1978). Briefly, the structure of the variation in RV can be expressed by the semivariance $\gamma(h)$, estimated by the following equation:

$$
\gamma(h)=\frac{1}{2 N(h)} \sum_{i=1}^{N(h)}[Z(i)-Z(i+h)]^{2}
$$

where $N(h)$ is the number of pairs of data points separated by the distance or lag $h$, and $Z(i)$ and $Z(i+h)$ are the recorded values at points $i$ and $i+h$. The log-log plot of $\gamma(h)$ (ordinate) as a function of distance class $(h)$ is termed the semivariogram, or variogram for simplicity. A distribution can be described by fractal geometry if there is a linear increase in semivariance with lag distance. This linear relationship is an indication of scale-dependent spatial structure. $D_{\mathrm{F}}$ is calculated from the slope $(m)$ of the scaling region (Burrough 1981, 1983):

$$
D_{\mathrm{F}}=(4-m) / 2
$$

Only scales less that half of the total length of the data set were considered because greater distances (higher lags) are more affected by low sample sizes and spurious properties of the data (Journel \& Huijbregts 1978). The values of $h$ included in the slope determination, and the subsequent estimate of the $D_{\mathrm{F}}$ were those that maximised the coefficient of determination $\left(\mathrm{r}^{2}\right)$ for the linear regression. The range of $h$ values included in the estimation of the $D_{\mathrm{F}}$ is termed the length of the scaling region, $L\left(D_{\mathrm{F}}\right)$, as it is over this range that scaling behaviour (spatial dependence) exists in the distribution. When variogram lines had multiple slopes (bent), a $D_{\mathrm{F}}$ was estimated for each segment. Slopes that were not significantly different from zero (as determined by least-squares regression analysis) were assumed to be random and were therefore attributed an estimated $D_{\mathrm{F}}=2$, indicating spatial independence and a lack of scaling behaviour.

Prior to analyses, data were found to be non-stationary; the original data were therefore detrended to zero mean and unit variance by fitting linear regressions, the residuals of which where then used for fractal analysis. All comparisons between estimated $D_{\mathrm{F}}$ were performed with 1-way ANOVA and independent $t$-tests. To determine whether there were statistical differences in the estimated $D_{\mathrm{F}}$ of 3 profiles of the array sampler, 95\% confidence intervals (CI) were calculated for the estimated $D_{\mathrm{F}}$ values using the $95 \% \mathrm{CI}$ of the regression coefficient (Zar 1984) in Eq. (2). Comparisons between the estimated $D_{\mathrm{F}}$ values of published profiles employed a non-parametric Mann-Whitney $U$-test as these data did not meet the requirements of parametric tests. All statistical analyses were performed using SPSS 10.0.5 statistical software.

\section{RESULTS}

\section{Physical environment}

Freshwater from the sewage treatment works appeared as a clear surface intrusion at the study site 

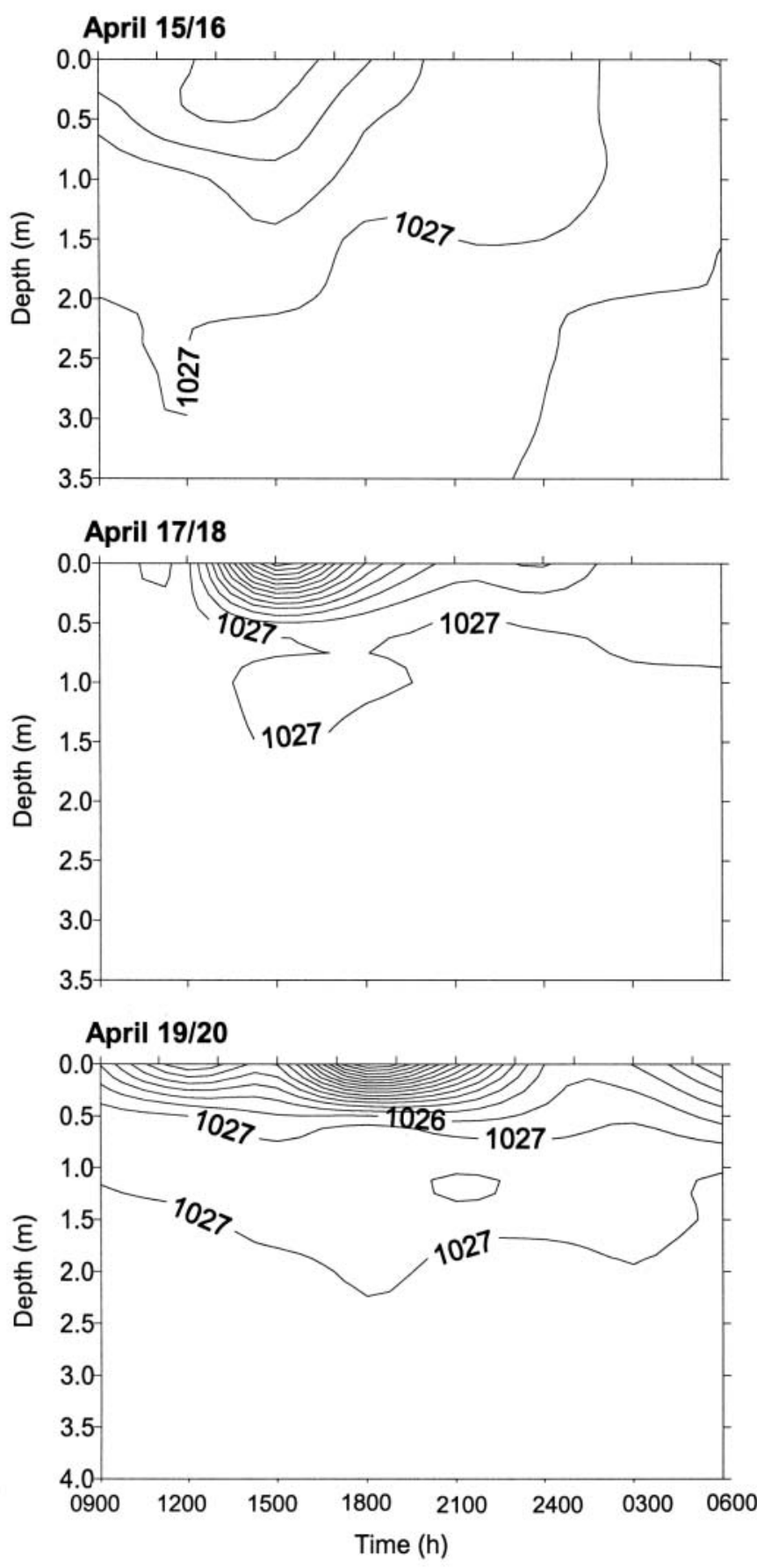

Fig. 1. Contour plot of sigma-t $\left(\sigma_{t}\right)$ distributions calculated from decimetre-scale temperature and salinity profiles. Contour lines are $0.5 \mathrm{~kg} \mathrm{~m}^{-3}$ and were interpolated using a kriging algorithm

and was responsible for the formation of a weak pycnocline on April 15/16 (Fig. 1A), and an intense pycnocline on April 17/18 and April 19/20 (Fig. 1B, C). The surface intrusion caused a decline in salinity across the first $0.5 \mathrm{~m}$ depth, of $1.5,7.9$ and $10 \%$, for each of the sequential sampling periods. On April 15/16 and April $17 / 18$, there was a corresponding decrease in surface temperature from 19.0 to 16.8 and $18.0^{\circ} \mathrm{C}$, respectively. However, on April 19/20 solar heating caused a slight increase in the temperature of surface waters to around $20^{\circ} \mathrm{C}$. Solar radiation, measured as PAR, was elevated on April 15/16 and April 19/20 with maximum values of 1865 and $1700 \mu \mathrm{E} \mathrm{m}^{-2} \mathrm{~s}^{-1}$, respectively, measured at 12:00 h. On April 17/18 levels were reduced to a maximum value of $250 \mu \mathrm{E} \mathrm{m} \mathrm{m}^{-2} \mathrm{~s}^{-1}$, measured at 15:00 $\mathrm{h}$, due to increased cloud cover on this day. Minimal tidal excursion of $0.30 \mathrm{~m}$ occurred on April 17/18, with increased tidal ranges of 1.03 to $2.27 \mathrm{~m}$ and 0.73 to $2.07 \mathrm{~m}$ on April 15/16 and April 19/20, respectively. Mean wind speed decreased from $5.6 \mathrm{~m} \mathrm{~s}^{-1}$ on April $15 / 16$ to 2.7 and $2.6 \mathrm{~m} . \mathrm{s}^{-1}$ on April 17/18 and on April $19 / 20$, respectively.

\section{Decimetre-scale profiles}

An example of the temporal shift in the vertical distribution of in vivo fluorescence measured during one of the $24 \mathrm{~h}$ sampling periods is shown in Fig. 2. Sample frequency was sufficient to identify the location of the fluorescence maxima and the limited variation in fluorescence within the maxima region. Measured intersample shifts in fluorescence were less than 2-fold in all profiles with the exception of April 19 at 12:00 h, when there was a 4 -fold increase in fluorescence between the surface and $25 \mathrm{~cm}$ depth sample. A vertical downward shift in the fluorescence maximum was common to all 3 sampling periods (e.g. Fig. 2) and coincided with an increase in surface irradiance during daylight hours.

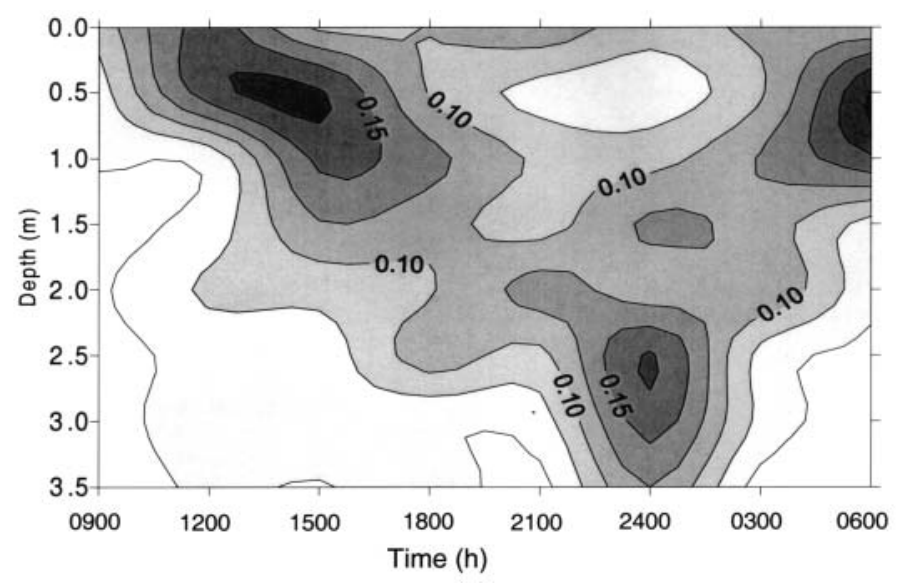

Fig. 2. Example contour plot of in vivo fluorescence profiles, measured at the decimetre scale, every $3 \mathrm{~h}$ for a $24 \mathrm{~h}$ period. Data shown are for April 17/18. Contour lines are 0.5 arbitrary fluorescence units (a.f.u.) and were interpolated using a kriging algorithm 


\section{Linear profiles}

The vertical structure of in vivo fluorescence, measured at the $5 \mathrm{~cm}$ sampling interval, was variable, including single-point maxima (e.g. Fig. 3A) and multiple-point increases or decreases in biomass (e.g. Fig. 3B). The inter-sample increase shown in Fig. 3A at $2.25 \mathrm{~m}$ was the largest observed point-to-point change in fluorescence (a 2.6-fold increase). A more common feature of the profiles was the presence of variable inter-sample fluorescence fluctuations embedded within larger scale changes, occurring over scales on the order of tens of centimetres (e.g. Fig. 3B). For all 6 profiles, the greatest variation was observed at depths directly above and below the fluorescence maxima.

\section{Array profiles}

Further detail of the inter-sample variation within the fluorescence maxima was observed in the array profiles (examples are shown in Fig. 4). The linear series of the array sampling device also revealed the presence of horizontal, in addition to vertical, intersample variation. Horizontal variation was greatest within the fluorescence maxima and at the surface (e.g. Fig. 4).

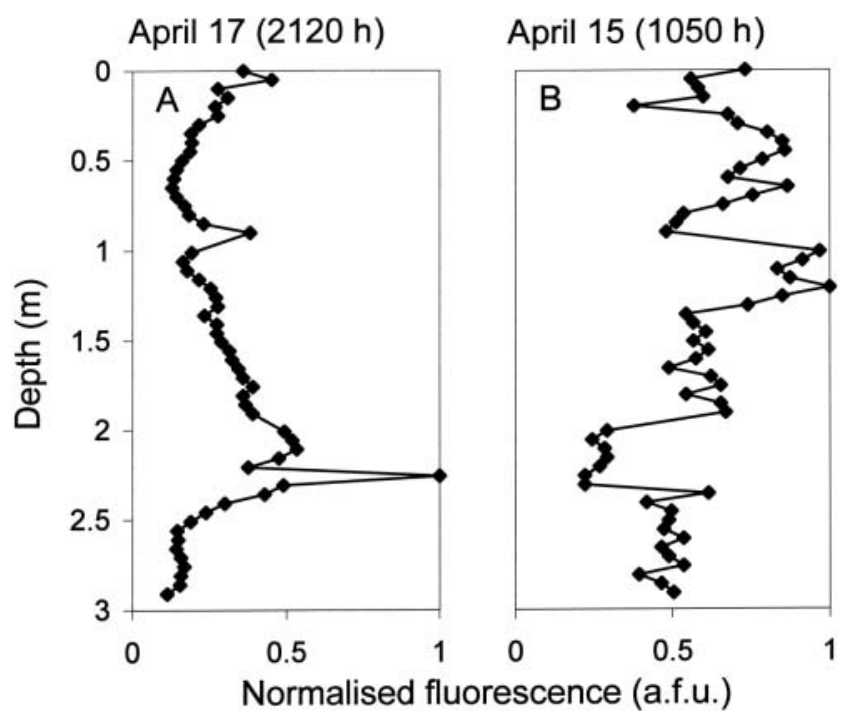

Fig. 3. Examples of the variation in the vertical microscale distribution of in vivo fluorescence, sampled over $3 \mathrm{~m}$, measured with the centimetre-scale linear sampling device on (A) April 17 at 21:20 h and on (B) April 15 at 10:50 h. Values normalised to the maximum fluorescence value of the profile

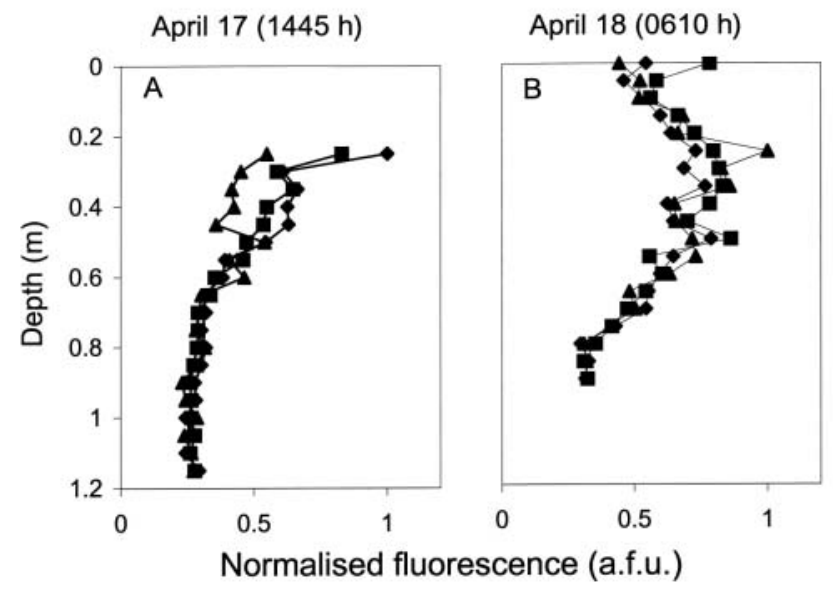

Fig. 4. Examples of the variation in the vertical microscale distribution of in vivo fluorescence, sampled over $1 \mathrm{~m}$ with the centimetre-scale array sampling device on (A) April 17 and on (B) April 18. Values normalised to the maximum fluorescence value of the sampling event. Different symbols denote the 3 parallel profiles of the array sampler

\section{Fractal analysis}

\section{Decimetre-scale profiles}

Fractal structure $\left(D_{\mathrm{F}}<2\right)$ was observed in $71 \%$ of in vivo fluorescence, $83 \%$ of temperature and $100 \%$ of salinity decimetre-scale profiles. The profiles of physical variables were generally more structured (lower $D_{\mathrm{F}}$ values) than the in vivo fluorescence profiles, with $50 \%$ of physical variable profile $D_{\mathrm{F}}$ values below 1.5 in comparison to $17 \%$ of in vivo fluorescence profiles (Fig. 5). However, when compared across all sampling events, the $D_{\mathrm{F}}$ values of in vivo fluorescence, temperature and salinity were not significantly different from each other $(\mathrm{p}=0.21, \mathrm{n}=24)$, with mean $D_{\mathrm{F}}=1.72$ (95\% CI: 1.63 to 1.81$), D_{\mathrm{F}}=1.63$ (95\% CI: 1.52 to 1.73 ) and $D_{\mathrm{F}}=1.61(95 \% \mathrm{CI}: 1.52$ to 1.70$)$, respectively. There was also no significant difference $(p>0.05)$ in $D_{\mathrm{F}}$ values compared between sampling days, when the $D_{\mathrm{F}}$ values of all 3 variables were grouped together $(\mathrm{n}=24)$ or analysed individually $(\mathrm{n}=6)$ (Fig. 6). Temporal changes in the $D_{\mathrm{F}}$ values of vertical profiles showed closest agreement on April 19/20 (Fig. 6C). In terms of the in vivo fluorescence profiles, there was a similarity in the temporal trend in $D_{\mathrm{F}}$ values for April 15/16 (Fig. 6A) and April 19/20 (Fig. 6C), observed as a gradual increase in complexity (decreasing $D_{\mathrm{F}}$ values) during the day and a loss of spatial structure $\left(D_{\mathrm{F}}\right.$ values approaching or equal to 2) at night. Maximum structural complexity of in vivo fluorescence distributions, measured on these days, coincided with maximum recorded light levels. This contrasted with in vivo fluorescence profiles on April 17/18, where $D_{\mathrm{F}}$ 


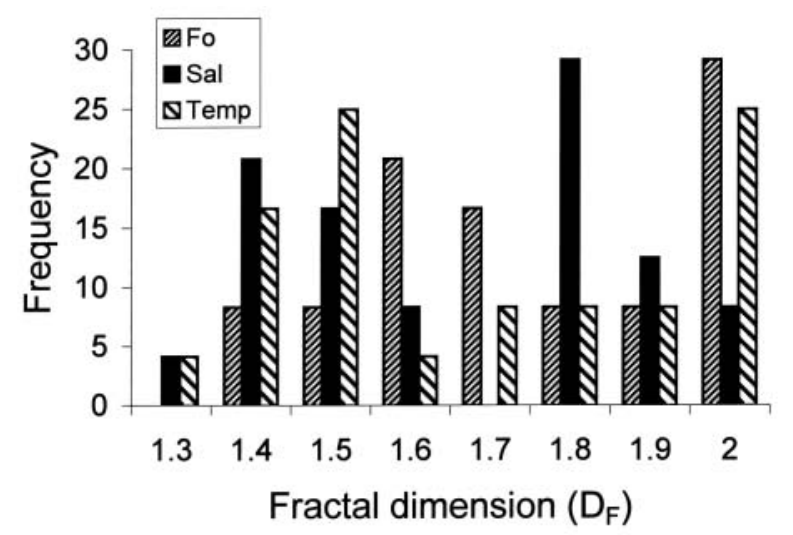

Fig. 5. Histogram of fractal dimension $\left(D_{\mathrm{F}}\right)$ values for in vivo fluorescence $\left(F_{\mathrm{o}}\right)$, temperature (Temp) and salinity (Sal) profiles, estimated from decimetre-scale profiles, for the entire study period

values indicated a decrease in structure during the day and no loss of structure at night (Fig. 6B). A feature that was consistent among all 3 days was the absence of structure $\left(D_{\mathrm{F}}=2\right)$ in the in vivo fluorescence profile sampled at 09:00 h. The one variable that did change as a function of day was the $L\left(D_{\mathrm{F}}\right)$ (Table 1). Values generally increased on April 17/18 for all variables (Table 1), with a number of profiles exhibiting scaling behaviour across the entire spatial range to a maximum lag distance of $175 \mathrm{~cm}$; however, the salinity distributions were the only variable to exhibit a significant increase $(\mathrm{p}<0.05)$ in $L\left(D_{\mathrm{F}}\right)$ values over time.

\section{Linear profiles}

All linear sampler profiles exhibited scaling behaviour $\left(D_{\mathrm{F}}<2\right)$ (Table 2). In addition, the daylight profiles were characterised by a secondary scaling region at longer

Table 1. Length of the scaling region $L\left(D_{\mathrm{F}}\right)(\mathrm{cm})$ estimated from log-log semivariograms for decimetre-scale profiles of in vivo fluorescence $\left(F_{0}\right)$, temperature $(T)$ and salinity $(S)$.

${ }^{*}$ Profiles that exhibited the maximum potential $L\left(D_{\mathrm{F}}\right)$

\begin{tabular}{|lcccccccccc|}
\hline \multirow{2}{*}{ Time } & \multicolumn{3}{c}{ April $15 / 16$} & \multicolumn{3}{c}{ April $17 / 18$} & \multicolumn{3}{c|}{ April $19 / 20$} \\
(h) & $F_{\mathrm{o}}$ & $T$ & $S$ & $F_{\mathrm{o}}$ & $T$ & $S$ & $F_{\mathrm{o}}$ & $T$ & $S$ \\
\hline $09: 00$ & 0 & 100 & 100 & 0 & 150 & $175^{*}$ & 0 & 100 & 100 \\
$12: 00$ & 150 & 125 & 100 & 100 & 150 & 100 & 150 & 100 & 100 \\
$15: 00$ & 125 & 0 & 100 & 100 & $175^{*}$ & 125 & 100 & 75 & 100 \\
$18: 00$ & $175^{*}$ & 0 & 125 & 75 & 100 & $175^{*}$ & 150 & 100 & $175^{*}$ \\
$21: 00$ & 0 & 100 & 100 & 125 & 0 & $175^{*}$ & 75 & 0 & $175^{*}$ \\
$24: 00$ & 100 & 150 & 100 & 75 & $175^{*}$ & $175^{*}$ & 0 & 100 & 100 \\
$03: 00$ & 0 & 100 & 100 & $175^{*}$ & 100 & 125 & 75 & 100 & 75 \\
$06: 00$ & 100 & 150 & 150 & 75 & 100 & 100 & 100 & 75 & 75 \\
\hline
\end{tabular}

spatial lags, resulting in a clear change in structure between the day and night profiles (e.g. Fig. 7A). For daylight profiles, there was an initial scaling region (mean $D_{\mathrm{F}}=1.74$ ) to a maximum spatial lag of $35 \mathrm{~cm}$ (Fig. 7A), followed by a secondary scaling region (mean $D_{\mathrm{F}}=1.29$ ) ranging in length from 20 to $35 \mathrm{~cm}$. The structure of the night profiles was similar for all 3 sampling days, in terms of $D_{\mathrm{F}}$ values (range: 1.55 to 1.65 ) and $L\left(D_{\mathrm{F}}\right.$ ) (range: 45 to $60 \mathrm{~cm}$ ). In addition, there was a consistent loss of spatialscale dependence at sampling intervals below $10 \mathrm{~cm}$ (Fig. 7B).
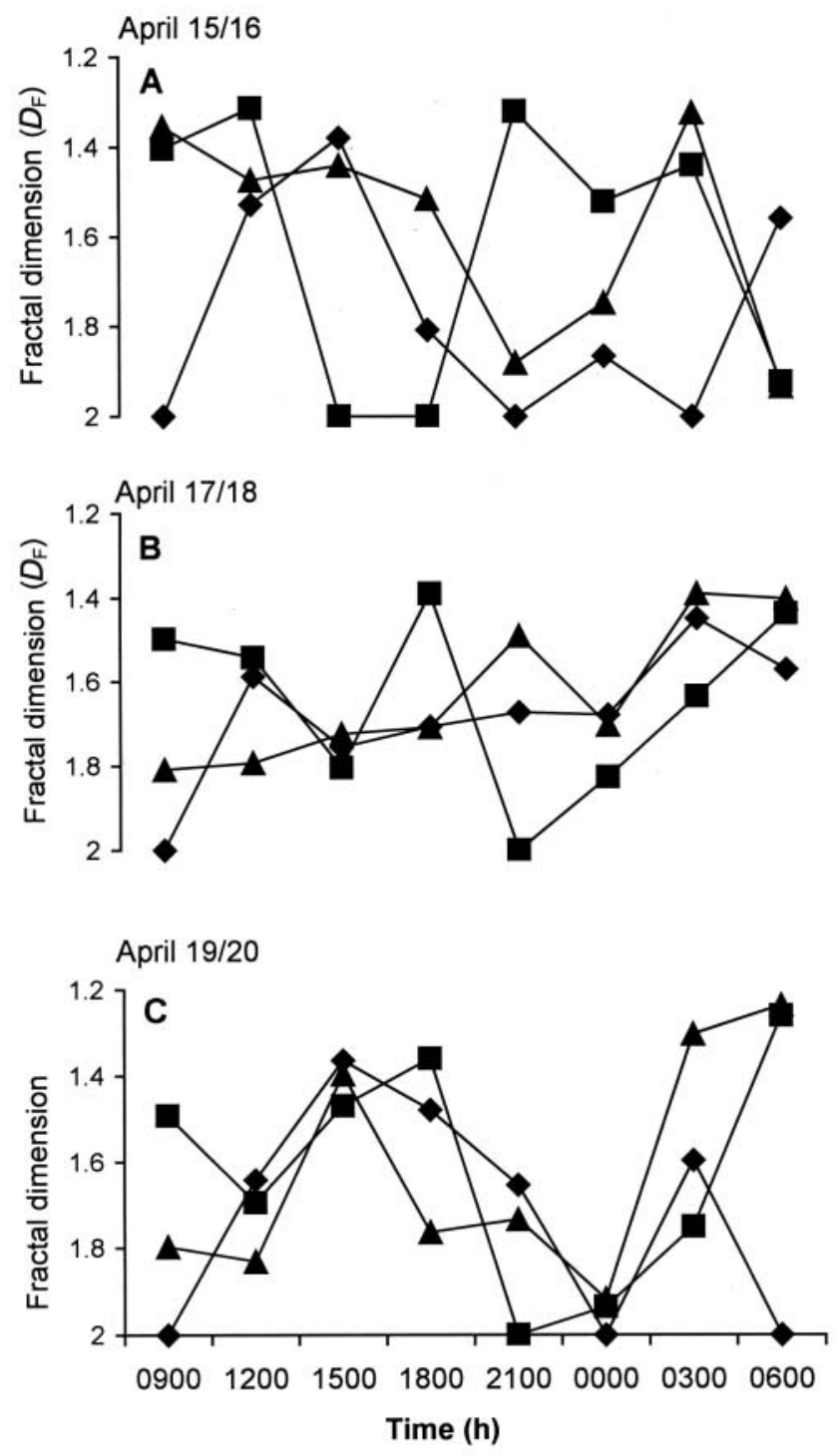

Fig. 6. Temporal variation in $D_{\mathrm{F}}$ values of in vivo fluorescence $(\bullet)$, temperature $(\mathbf{\square})$ and salinity $(\boldsymbol{\Lambda})$ pump-derived samples, for (A) April 15/16, (B) April 17/18 and (C) April 19/20. The $y$-axis values are in reverse to aid the interpretation that a decrease in $D_{\mathrm{F}}$ value, shift up the $y$-axis, is indicative of an increase in structural complexity. $D_{\mathrm{F}}=2$ indicates an absence of scaling behaviour 
Table 2. Sampling details, estimated fractal dimension $\left(D_{\mathrm{F}}\right)$ and $L\left(D_{\mathrm{F}}\right)$ for centimetre-scale linear profiles. The semivariograms of profiles A and B are presented as an example in Fig. $7.1^{\circ}$ and $2^{\circ}$ values correspond to the primary and secondary scaling regions, respectively

\begin{tabular}{|lccccc|}
\hline Profile Date & $\begin{array}{c}\text { Time } \\
\text { (h) }\end{array}$ & $1^{\circ} D_{\mathrm{F}}$ & $2^{\circ} D_{\mathrm{F}}$ & $\begin{array}{c}\text { Length of scaling } \\
\text { region }(\mathrm{cm})\end{array}$ \\
\hline A & April 15 & $10: 50$ & 1.70 & 0.85 & $35\left(1^{\circ}\right)+25\left(2^{\circ}\right)$ \\
B & April 17 & $12: 10$ & 1.81 & 1.60 & $30\left(1^{\circ}\right)+75\left(2^{\circ}\right)$ \\
C & April 19 & $09: 00$ & 1.70 & 1.42 & $20\left(1^{\circ}\right)+15\left(2^{\circ}\right)$ \\
D & April 15 & $20: 40$ & 1.65 & - & 60 \\
E & April 17 & $21: 20$ & 1.63 & - & 60 \\
F & April 19 & $21: 20$ & 1.55 & - & 45 \\
\hline
\end{tabular}

Table 3. Sampling details, $D_{\mathrm{F}}$ and $L\left(D_{\mathrm{F}}\right)$ for centimetre-scale array in vivo fluorescence samples, presented in Fig. 8. 'Array profile' refers to the three 19-point vertical profiles that were sampled simultaneously during each sampling event

\begin{tabular}{|cccccccccc|}
\hline \multirow{2}{*}{$\begin{array}{c}\text { Sampling } \\
\text { event }\end{array}$} & Date & \multirow{2}{*}{ Time } & \multicolumn{4}{c}{$D_{\mathrm{F}}$} & \multicolumn{4}{c|}{$L\left(D_{\mathrm{F}}\right)(\mathrm{cm})$} \\
& & (h) & \multicolumn{2}{c|}{ Array profile } & \multicolumn{3}{c|}{ Array profile } \\
& & & 1 & 2 & 3 & 1 & 2 & 3 \\
\hline 1 & Apr 15 & $16: 00$ & 1.70 & 1.66 & 1.82 & 15 & 20 & 25 \\
2 & Apr 16 & $06: 00$ & 2.00 & 1.84 & 2.00 & - & 15 & - \\
3 & Apr 17 & $14: 45$ & 1.52 & 1.40 & 2.00 & 30 & 35 & - \\
4 & Apr 18 & $06: 10$ & 1.53 & 1.44 & 1.49 & 35 & 30 & 20 \\
5 & Apr 19 & $15: 00$ & 1.81 & 1.58 & 1.66 & 20 & 15 & 20 \\
6 & Apr 20 & $04: 55$ & 1.66 & 1.48 & 1.52 & 25 & 25 & 25 \\
& & & & & & & & & \\
\hline
\end{tabular}

\section{Array profiles}

Fractal structure was observed in $83 \%$ of the centimetre-scale array profiles. The estimated $D_{\mathrm{F}}$ values (Table 3) were not significantly different from those of the initial scaling regions of the linear profiles (Table 2), or the decimetre scale in vivo fluorescence profiles ( $\mathrm{p}=$ 0.702). In contrast to the $D_{\mathrm{F}}$ values of the decimetrescale and linear in vivo fluorescence profiles, array $D_{\mathrm{F}}$ values did vary significantly with sampling period $(\mathrm{p}<$ 0.05; Table 3). Specifically, there was a significant decrease in $D_{\mathrm{F}}$ values from April 15/16 (mean $D_{\mathrm{F}}=$ $1.84 ; 95 \%$ CI: 1.68 to 1.99 ) to April $17 / 18$ (mean $D_{\mathrm{F}}=$ 1.56 ; $95 \% \mathrm{CI}: 1.33$ to $1.79, \mathrm{p}<0.05)$ and from April 15/16 to April 19/20 (mean $D_{\mathrm{F}}=1.62 ; 95 \% \mathrm{CI}: 1.50$ to $1.74, \mathrm{p}<0.05)$. There was no difference in values between April 17/18 and 19/20.

Significant differences were identified between the profiles of the array sampler, thereby resolving horizontal structural variation to $7 \mathrm{~cm}$ (Fig. 7). Disparity between array profiles (identified by comparison of the $95 \%$ CI of $D_{F}$ values; see methods for details) was determined for $50 \%$ of the array sampling events (Fig. 8, Table 3). On April 19, $D_{\text {F values of only profiles }}$ 1 and 3 differed, whereas on April 17 and 20, $D_{\text {F }}$ values of profile 1 differed from those of both profiles 2 and 3 .

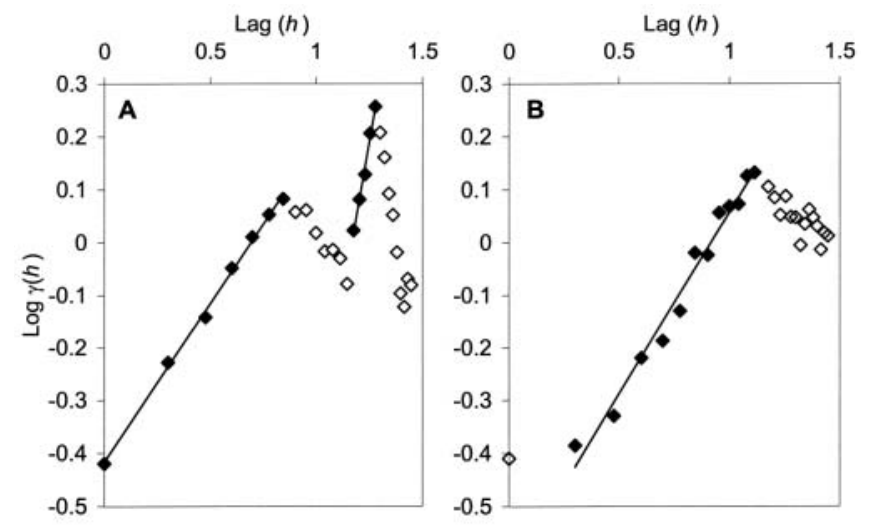

Fig. 7. Sample log-log semivariograms of centimetre-scale linear sampler (A) 'day' and (B) 'night' vertical profiles collected on April 15/17. Length of the scaling regions $L\left(D_{\mathrm{F}}\right)$ is denoted by solid symbols. Open symbols indicate a lack of scale dependence. Labelled profiles, together with estimated $D_{\mathrm{F}}$ and $L\left(D_{\mathrm{F}}\right)$ values, are presented in Table 2

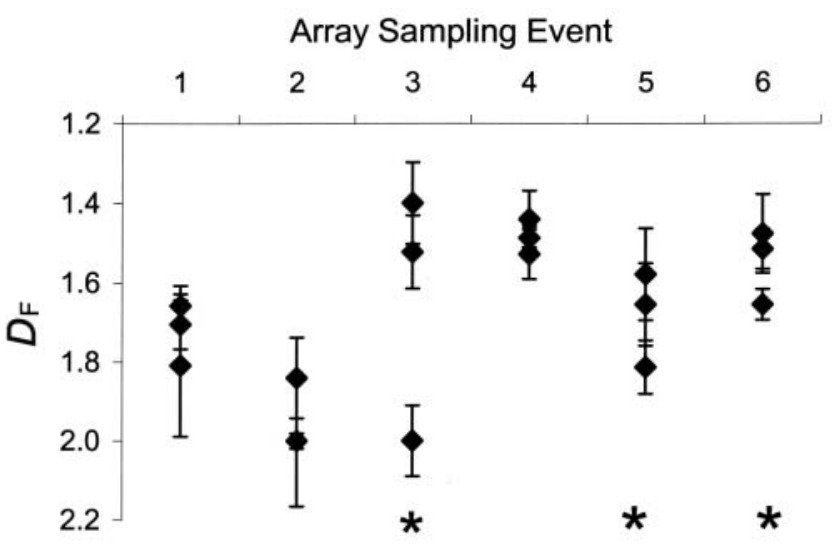

Fig. 8. Variation in estimated $D_{\mathrm{F}}$ values of centimetre-scale array profiles. Details of sampling events are given in Table 3. Error bars are $95 \%$ confidence intervals (CI) of the $D_{\mathrm{F}}$ estimate. Profiles groups marked with an asterisk $\left({ }^{*}\right)$ contain 1 profile that has significantly different structure from the remaining profiles. The $y$-axis values are in reverse to aid the interpretation that a decrease in $D_{\mathrm{F}}$ value, shift up the $y$-axis, is indicative of an increase in structural complexity. $D_{\mathrm{F}}=2$ indicates an absence of scaling behaviour. Labelled profiles, together with estimated $D_{\mathrm{F}}$ values and $L\left(D_{\mathrm{F}}\right)$, are presented in Table 3.

\section{DISCUSSION}

For $87 \%$ of measured profiles, the structure of vertical distributions of biological and physical variables exhibited spatial-scale dependence and can therefore be characterised by fractal geometry. The implication of this is that variation is ordered into regular structures. We present further evidence of similarity between in vivo fluorescence profiles sampled at $25 \mathrm{~cm}$ 
and $5 \mathrm{~cm}$ resolution, as identified by comparable $D_{\mathrm{F}}$ values; suggesting that both decimetre- and centimetre-scale phytoplankton distributions are structurally organised by similar processes.

The estimated mean $D_{\mathrm{F}}$ for temperature, salinity and in vivo fluorescence profiles observed in this study fall within the same range as those reported elsewhere for large-scale vertical profiles (Seuront \& Lagadeuc 1998) and time series (Seuront \& Lagadeuc 1997) of the same variables. Our results indicate, therefore, that the same structure observed at large scales extends down to scales of decimetres and centimetres. The reported $D_{\mathrm{F}}$ values identified weaker spatial dependence (higher $D_{\mathrm{F}}$ values) in measured profiles than those from landforms (Mandelbrot 1977), river flows, silt deposition and climate data (Mandelbrot \& Wallis 1969), but stronger spatial dependence (lower $D_{\mathrm{F}}$ values) than the variability estimated from soils (Burrough 1981, 1983), the spatial patterns of plant communities (Palmer 1988), and the spatial distribution of marine birds and their prey (Russel et al. 1992). Seuront \& Lagadeuc (1997) proposed that the $D_{\mathrm{F}}$ may be directly related to the time scale of the physical mechanism structuring the distributions, such that large-scale processes, including those influencing landform, result in low $D_{\mathrm{F}}$, while short-range processes, such as those operating in the planktonic environment (e.g. turbulent mixing), produce higher $D_{\mathrm{F}}$. For this relationship to follow, the $D_{\mathrm{F}}$ values reported here and by Seuront \& Lagadeuc $(1997,1998)$ would be higher than those of the distributions listed above, as the time scale of planktonic processes is in the order of seconds rather than months (e.g. marine bird distributions) or $100 \mathrm{yr}$ (e.g. seismic frequency). The fact that reported $D_{\mathrm{F}}$ values do not adhere to this linear relationship suggests that the influence of physical structuring mechanisms on the $D_{\mathrm{F}}$ of the distribution is more complex than proposed by Seuront \& Lagadeuc (1997).

Azovsky et al. (2000) proposed 2 levels of structuring mechanisms responsible for generating scale dependence, or 'fractality', in (predominantly terrestrial) biological distributions. Firstly, biological distributions are created by an abiotic 'template' upon which organisms are organised; the distributions of many abiotic factors are themselves fractal (e.g. those listed in Burrough 1981). For the planktonic environment this equates to biological particles being organised as passive tracers. Secondly, that fractal spatial pattern is the result of community self-organisation, which is then further transformed into other spatial structures (e.g. patches, gradients) under the influence of abiotic structuring mechanisms. Due to the time scale of the present study, here we use the term 'community response' to refer primarily to the behavioural response of cells to physical gradients, rather than in situ growth.
The physical structure, or form, of the abiotic template in the planktonic environment can be inferred from the distribution of conservative tracers (temperature and salinity). Comparisons between the $D_{\mathrm{F}}$ values of in vivo fluorescence and abiotic factors would therefore indicate whether the distribution of biological and physical distributions are controlled by the same structuring processes, akin to the comparison of temperature and chlorophyll a variance spectra (Platt \& Denman 1975, Denman et al. 1977). The $D_{\mathrm{F}}$ values of in vivo fluorescence, temperature and salinity profiles measured in the Port River were not significantly different from each other, as verified by the similarity of the $95 \%$ CI of the estimated $D_{\mathrm{F}}$ distributions, thereby implying strong coupling in the organisation of physical and in vivo fluorescence distributions. In estuarine systems the distribution of passive tracers is primarily controlled by the interaction of fresh and saltwater inputs, resulting in the formation of a salinity-driven pycnocline. The position, intensity and stability of the pycnocline in turn controls the distribution of phytoplankton through processes of interface accumulation (e.g. Brandt et al. 1986) and the control of nutrient availability (e.g. Webb \& D'Elia 1980). In the Port River estuary the pycnocline is ephemeral (Fig. 1) due to the intermittent input of freshwater from the sewage treatment works. Consequently, there was no apparent change in the biological or physical structure of measured profiles ( $D_{\mathrm{F}}$ values) coincident with the arrival of the freshwater intrusion and pycnocline formation. The lack of a change in biological and physical structure during the intense stratification of the water column (e.g. Fig. 1B,C) may in part be due to the fact that the pycnocline was confined to the upper $0.5 \mathrm{~m}$ of the water column, and the sampling resolution of the decimetre samples $(25 \mathrm{~cm})$ may therefore have been insufficient to identify a change in structure ( $D_{\mathrm{F}}$ value) within this region. This may be addressed by increased sampling resolution for physical variables in future studies.

The distribution of passive tracers is also modified by in situ mixing. In this study, mixing was minimal due to reduced tidal movement (neap tidal period) and low wind speeds. There was a slight increase in tidal excursion on April 15/16 and April 19/20 in comparison to April 17/18; however, there was no comparable shift in the $D_{\mathrm{F}}$ values of any of the measured variables. The variable that did change on April 17/18 was the $L\left(D_{\mathrm{F}}\right)$ of the salinity profiles (Table 1 ) with an increased occurrence of maximal scaling ranges: $L\left(D_{\mathrm{F}}\right)=145 \mathrm{~cm}$. This is an indication of new scales of variation (Burrough 1983), implying that in the absence of tidal mixing, the structure of measured distributions spreads to larger scales than in the presence of mixing. This relationship could be verified by additional sampling during periods of 
increased mixing. That $L\left(D_{\mathrm{F}}\right)$ values were greater for salinity profiles also highlights the fact that while the mean $D_{\mathrm{F}}$ values were not significantly different, marked temporal differences in the observed structure of measured variables did occur. The nature of the short-term processes responsible for the observed differences in the distributions of abiotic factors are unclear. However, the occurrence of sampling events where the structure of the in vivo fluorescence distribution deviated from those of the passive tracers (e.g. 09:00 h on April 16, 18 and 20 ; Fig. 6) suggests the presence of community selforganisation or behavioural processes.

The results of both decimetre- and centimetre-scale linear distributions suggest that in vivo fluorescence distributions may be further modified by the behavioural response of the resident phytoplankton communities to changes in ambient light. The structure of decimetre-scale in vivo fluorescence profiles exhibited a clear diurnal effect on April 15/16 and April 19/20 that was not present on April 17/18 (Fig. 6). Both in situ mixing and ambient lights levels were elevated on these days. However, the diurnal trend in the change in $D_{\mathrm{F}}$ values suggests that light is more important than effects of mixing. The correlation between light levels and increased structure in the decimetre-scale distributions is high. Maximum levels of spatial complexity were recorded during the periods of highest incident light (Fig. 6A,C), while a loss of structure $\left(D_{\mathrm{F}}=2\right)$ at 09:00 h, on all 3 days (Fig. 6), may be attributed to the reorganisation of the phototactic cells in response to increasing light levels. A consistent diurnal effect was also observed in the centimetre-scale linear profiles, with daytime profiles identifying the existence of multiple scaling regions, compared to a single region in the night profiles (e.g. Fig. 7). While we recognise that convective mixing processes may also be significant at night, there is no evidence of water column overturn in the sigma-t distributions (Fig. 1). The potential influence of light on the behaviour and distribution of Port River Estuary phytoplankton is particularly significant due to the frequent dominance of resident communities by phototactic motile flagellate species (Cannon 1993, Hallegraeff et al. 1988, Ault et al. 2000), with specific resident taxa shown to modify their vertical distribution in response to light to maximise photosynthetic yield (Ault 2000). The observed downward movement of the fluorescence maximum during the day, returning to the surface in the early morning (e.g. Fig. 2), is a common phenomenon for vertically migrating dinoflagellate species (e.g. Hasle 1950, Blasco 1978, Villarino et al. 1995). The presence of taxa capable of light-induced, diel vertical migration, including the phytoflagellates, Prorocentrum triestinium and Gymnodinium sp., was confirmed by the taxonomic observations of T. Ault (pers. comm.).
The existence of multiple scaling regions in daylight (Fig. 7) indicates the influence of more than one structuring process. Similar scaling behaviour, termed 'partial similarity' (Mandelbrot 1977, 1983), has been reported for soil and landscape properties (Burrough 1981, 1983), landscape patterns (Palmer 1988) and in temporal series of temperature, salinity and in vivo fluorescence (Seuront \& Lagadeuc 1997), where they have been attributed to the existence of multiple structuring processes. The observed change in $D_{\mathrm{F}}$ values between the primary and secondary region of the semivariogram (e.g. Fig. 7A) is similar to the 'Platt-knee' example in the spectral analysis of phytoplankton spatial data. The switch in the spectral power law at scales between 0.2 and $20 \mathrm{~km}$ corresponds to the switch from the dominance of physical to biological structuring mechanisms (Platt \& Denman 1975, Denman \& Platt 1976, Denman et al. 1977). The multiple scaling regions in our data highlight the potential for fractal geometry in quantifying shifts in the structure of centimetre-scale distributions (cf. Sugihara \& May 1990, Hastings \& Sugihara 1993). In this study, the similarity between the $D_{\mathrm{F}}$ values of the primary region of day profiles and night profiles suggests that the dominant structuring mechanism may not be light. The secondary scaling region is present only during the day, suggesting that the behavioural response to light becomes important at scales of greater than $70 \mathrm{~cm}$. The decrease in $D_{\mathrm{F}}$ values in the secondary region indicated increased complexity and were similar to those observed during periods of maximum ambient light in the decimetre-scale distributions, further indicating the link between light and increased structural complexity.

The $D_{\mathrm{F}}$ values of in vivo fluorescence for the array, linear and decimetre profiles were the same, again indicating similar structuring processes. However, in contrast to the decimetre-scale profiles, the $D_{\mathrm{F}}$ of the array profiles did decrease significantly from the first sampling period to the second and third sampling periods. The 2 potential structuring mechanisms that also changed between the first period, compared with the second and third periods, were wind velocity and the taxonomic composition of the phytoplankton community.

The contribution of wind to turbulent mixing at a specified depth can be estimated from the magnitude of the wind velocity at the surface (MacKenzie \& Leggett 1993). Energy input to the system at the largest scale is progressively transferred to smaller and smaller scales via a 'cascade of turbulent eddies', down to the viscous scale (termed the Kolmogorov length scale, $L_{\mathrm{k}}$ ), where energy is dissipated as heat (Denman \& Gargett 1995). To quantify changes in the mixing environment over the period of the study, wind data were used to estimate the spatial limit of 'Kolmogorov' eddies $\left(L_{\mathrm{k}}\right)$, the theoretical length scale where kinetic 
energy is dissipated as heat (Denman \& Gargett 1995) and therefore the minimum length scale over which mixing may influence spatial distributions. We recognise that in situ mixing has tidal and wind-driven components; however, vertical velocity profiles were not available to quantify the tidal component, which we expect to be minimal due to neap tidal conditions. The energy dissipation rate $(\varepsilon)$ of wind energy to turbulent energy $\left(\mathrm{m}^{2} \mathrm{~s}^{-3}\right)$ was calculated from $W^{3} / \mathrm{z}$, where $W$ is the wind speed $\left(\mathrm{m} \mathrm{s}^{-1}\right)$ and $\mathrm{z}$ is the depth $(\mathrm{m})$ (MacKenzie \& Leggett 1993). The energy dissipation rate is then linked to the length of the Kolmogorov eddies $\left(L_{\mathrm{k}}\right)$ by $L_{\mathrm{k}}=\left(v^{3} / \varepsilon\right)^{1 / 4}$, where $v$ is the kinematic viscosity $\left(v=1.047 \times 10^{-6} \mathrm{~m}^{2} \mathrm{~s}^{-1}\right.$ at $20^{\circ} \mathrm{C}$, Vogel 1994). Mean $L_{\mathrm{k}}$ values, calculated for a depth of $1.5 \mathrm{~m}$, increased from $0.12 \mathrm{~cm}$ (April 15/16) to $0.25 \mathrm{~cm}$ and $0.22 \mathrm{~cm}$ (April $17 / 18$ and 19/20), due to the decrease in wind speed. The predicted change in $D_{\mathrm{F}}$ with response to an increase in $L_{\mathrm{k}}$ values would be a decrease in $D_{\mathrm{F}}$ values, due to the increased influence of longer-range effects (larger eddy size), which is in direct agreement with the results presented here (mean decrease from $D_{\mathrm{F}}=$ 1.84 for April 15/16 to $D_{\mathrm{F}}=1.62$ for April 19/20). The lowest mean $D_{\mathrm{F}}$ values (1.56) were for the sampling period that coincided with the neap tide (April 17/18). The tidal component of mixing was minimal for this period, which would have resulted in a further decrease in energy dissipation rates and therefore a further increase in $L_{\mathrm{k}}$ length scales, suggesting a direct inverse relationship between $L_{\mathrm{k}}$ and $D_{\mathrm{F}}$ values. Oceanographic observations suggest that the actual scale at which turbulent kinetic energy is dissipated to heat is 10 times greater than $L_{\mathrm{k}}$ (Gibson 1980, Oakey \& Elliot 1982), with eddies more accurately viewed as vortices with greater length than diameter (Estrada \& Berdalet 1997). If this is the case, then based on the Kolmogorov lengths calculated above, the centimetre scale is the correct length scale for sampling sheardriven modifications of cell distributions. The results presented here do indicate a direct relationship between mixing and the spatial structure of phytoplankton distributions.

The shift in mixing conditions may have been sufficient to drive the changes in measured $D_{\mathrm{F}}$ values. The assumption here is that phytoplankton cells are behaving as passive tracers, which may not necessarily be the case. Evidence suggests that, at the centimetrescale, phytoplankton cells may be organised into a coherent spatial structure due to the interaction of cell morphology and motility with local shear. The focusing of cells due to the interaction of motility and shear is termed 'gyrotaxis' and was first described in detail by Kessler (1985). Directed swimming by motile phytoplankton is a behavioural response to physical gradients (chemotaxis, e.g. Kessler 1986; geotaxis, e.g. Chil- dress et al. 1975; and phototaxis, e.g. Green \& Diez 1995); gyrotaxis is therefore the second example of a community response to the abiotic template. Field observations of in situ gyrotactic clusters were made by Kils (1993), who reported an increase in abundance of several orders of magnitude over a distance of $1 \mathrm{~cm}$ during a bloom of the tintinnid Stenosemella nucula and the dinoflagellate Prorocentrum minimum. Similar distributions have been observed in the Port River Estuary (pers. obs.) during a dense bloom of the dinoflagellate Prorocentrum triestinium, which occurred on the neap tide (i.e. minimal tidal movement) during very calm weather conditions. The assumption is that gyrotactic focusing occurs only in high cell concentrations where there is sufficient biological activity to generate local shear; Kessler (1985) used cell concentrations of $10^{4}$ to $10^{7}$ cells cm${ }^{-3}$. The question that arises is whether, in the absence of biologically driven shear, cells would respond to turbulence shear due to in situ mixing. Mitchell et al. (1990) reported that the shear across a microplankter's surface, due to oceanic mixed-layer turbulence, is the correct magnitude to produce millimetre-sized clusters of motile plankton and proposed that, in the presence of multiple motile species, differences in geometries (and therefore gravitational torques) may result in taxonomic sorting and ultimately changes in the microscale distribution of cells in the ocean. In addition, Katz et al. (1999) observed rheotactic (morphologically driven migration in shear) clusters of the elongated diatoms Chaetoceros ebenii and Ditylum brightwellii. The potential for the taxon-specific reorganisation of cells therefore exists for motile and non-motile species.

The taxonomic shift that occurred in the Port River during the sampling period was from a diatom-dominated on April 15/16 to a phytoflagellate-dominated on $17 / 18$ and, finally, to a mixed community on 19/20 (T. Ault pers. comm.). We propose that this taxonomic change, combined with the changes in mixing conditions, further modified resultant phytoplankton distributions due to gyrotactic and rheotactic reorganisation. For example, the lowest mean $D_{\mathrm{F}}$ values (indicating greatest structural complexity) were observed for the period April 17/18. This was a period of decreased tidal and wind-driven mixing and coincided with a period when the phytoplankton community was dominated by flagellate species, which are gyrotactic (Kessler 1985, Pedley \& Kessler 1990).

To determine whether increased spatial complexity is a common feature of flagellate-dominated phytoplankton communities, we compare the results presented here with $D_{\mathrm{F}}$ values calculated for vertical phytoplankton profiles in the literature (Table 4). For species counts recorded in Southern Kattegat, Denmark (Tiselius et al. 1994), the mean $D_{\mathrm{F}}$ of flagellate 


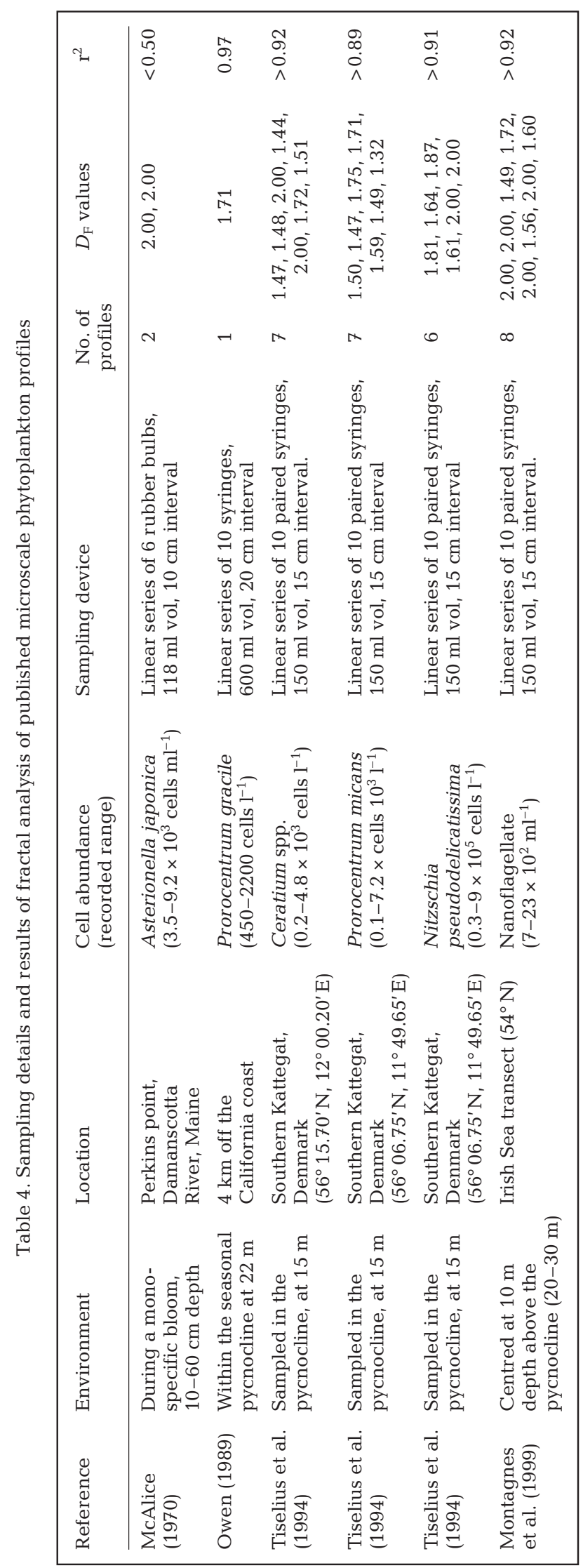

species' profiles was significantly lower (Mann-Whitney $U$-test, $\mathrm{p}<0.05)$, and therefore more complex, than that of the diatom species. Mean $D_{\mathrm{F}}$ values were 1.66 and 1.55 for Ceratium sp. and Prorocentrum micans, respectively, compared with a mean $D_{\mathrm{F}}$ value of 1.82 for Nitzschia pseudodelicatissima. The results from other locations are either too variable (e.g. Montagnes et al. 1999) or contain insufficient replication (e.g. McAlice 1970, Owen 1989) to determine whether increased structural complexity in flagellate-dominated communities is a consistent feature, but fractal analysis will allow us to address this question in the future.

The most striking result of this study was the discovery of disparity in the structure of closely spaced $(7 \mathrm{~cm}$ interval) centimetre-scale array profiles. While horizontal variation similar to that shown in Fig. 2A was known (e.g. Mitchell \& Fuhrman 1989, Owen 1989, Katz et al. 1999), changes in the structure of microscale vertical distributions, sampled over intervals of centimetres (Fig. 8), are reported here for the first time. A significant difference in the vertical structure of array replicates was observed in $50 \%$ of the array replicates, suggesting that this is a consistent phenomenon. Changes in the structure of vertical distributions over such short distances and time scales (hours) implies spatial and temporal variability in the influence of dominant structuring mechanisms.

The presence of multiple structuring mechanisms, as inferred from line breaks (e.g. Fig. 7A), means that biological-physical interactions observed at the metre to kilometre scales (Mackas et al. 1985, Denman 1994, Denman \& Gargett 1995) extend down to the centimetre scale. These results highlight the applicability of fractal analysis to studies of plankton ecology. The use of fractal analysis to quantify the spatial structure of distributions may provide a consistent framework for direct comparison of phytoplankton distributions sampled over multiple scales from varying planktonic environments. Quantification of spatial and temporal structure of these highly fluctuating patterns may provide further understanding of the processes operating at these scales, including the response of grazers to heterogeneous prey distributions (Buskey \& Stoecker 1989, Tiselius 1992), modelling the dynamics of phytoplankton populations (e.g. Baird \& Emsley 1999), and may provide yet further evidence of the importance of environmental complexity in further resolving the 'paradox of the plankton' (Hutchinson 1961).

Acknowledgements. We are very grateful to D. Edyvean for his construction of the syringe sampling devices. We are also thankful to T. Ault, P. Strutton, J. Seymour, P. Greig and M. Hale for assistance in the field, and to Primary Industries of South Australia at Port Adelaide, for access to the field site. In addition, we would like to offer our thanks to L. Seuront for 
verifying the correct use and interpretation of the fractal analysis techniques employed, and to 3 anonymous reviewers for their helpful suggestions and comments on the manuscript. Sea level data were supplied by the National Tidal Facility, The Flinders University of South Australia, copyright reserved. Wind data were supplied by the Ports Corp., South Australia. Funding for this research was provided by a Flinders University Research Budget grant to R.W. 1997 and by the Australian Research Council. R.W. was supported by an Australian Postgraduate Award.

\section{LITERATURE CITED}

Ault T (2000) Vertical migration by the marine dinoflagellate Prorocentrum triestinium maximises photosynthetic yield. Oecologia 125:466-475

Ault T, Velzeboer R, Zammit R (2000) Influence of nutrient availability on phytoplankton growth and community structure in the Port Adelaide River, Australia: bioassy assessment of potential nutrient limitation. Hydrobiologia 429:89-103

Azovsky AI, Chertoprood MV, Kucheruk NV, Rybnikov PV, Sapozhnikov FV (2000) Fractal properties of spatial distribution of intertidal benthic communities. Mar Biol 136: 581-590

Baird ME, Emsley S (1999) Towards a mechanistic model of plankton population dynamics. J Plankton Res 21:85-126

Baker AL, Baker KK, Tyler PA (1985) A family of pneumatically-operated thin layer samplers for replicate sampling of heterogeneous water columns. Hydrobiologia 122: 207-211

Bjørnsen PK, Nielsen TG (1991) Decimeter scale heterogeneity in the plankton during a bloom of Gyrodinium aureolum. Mar Ecol Prog Ser 73:263-267

Blackburn N, Fenchel T, Mitchell JG (1998) Microscale nutrient patches in planktonic habitats shown by chemotactic bacteria. Science 282:2254-2256

Blasco D (1978) Observations on the diel migration of marine dinoflagellates off the Baja California coast. Mar Biol 46:41-47

Brandt A, Sarabun CC, Seliger HH, Tyler MA (1986) The effects of a broad spectrum of physical activity on the biological processes in Chesapeake Bay. In: Nihoul JCL (ed) Marine interfaces ecohydrodynamics. Elsevier Science Publishers, Amsterdam, p 361-384

Burrough PA (1981) Fractal dimensions of landscapes and other environmental data. Nature 294:240-242

Burrough PA (1983) Multiscale sources of spatial variation in soil. I. The application of fractal concepts to nested levels of soil variation. J Soil Sci 43:577-597

Buskey EJ, Stoeker DK (1989) Behavioral responses of the marine tintinnid Favella sp. to phytoplankton: influence of chemical, mechanical and photic stimuli. J Exp Mar Biol Ecol 132:1-16

Cannon JA (1993) Germination of the toxic dinoflagellate Alexandrium minutum, from sediments in the port river, South Australia. In: Smayda TJ, Shimizu Y (eds) Toxic phytoplankton blooms in the sea. Elsevier Science Publishers, Amsterdam, p 103-107

Cassie RM (1963) Microdistribution of plankton. Oceanogr Mar Biol Annu Rev 1:223-252

Chatfield C (1989) The analysis of time series: an introduction, 4th edn. Chapman \& Hall, London

Childress S, Levandowsky M, Spiegel EA (1975) Pattern formation in a suspension of swimming micro-organisms: equations and stability theory. J Fluid Mech 63:591-613
Cowles TJ, Desiderio RA, Neuer WS (1993) In situ characterisation of phytoplankton from vertical profiles of fluorescence spectra. Mar Biol 115:217-222

Denman KL (1994) Scale-determining biological-physical interactions in oceanic food webs. In: Giller PS, Hildrew AG, Raffaelli DG (eds) Aquatic ecology: scale, pattern, and process. Blackwell Science, Oxford, p 377-402

Denman KL, Gargett AE (1995) Biological-physical interactions in the upper ocean: the role of vertical and small scale transport processes. Annu Rev Fluid Mech 27: 225-255

Denman KL, Powell TM (1984) Effects of physical processes on planktonic ecosystems in coastal ocean. Oceanogr Mar Biol Annu Rev 22:125-168

Denman KL, Okubo A, Platt T (1977) The chlorophyll fluctuation spectrum in the sea. Limnol Oceanogr 22:1033-1038

Derenbach JB, Astheimer H, Hansen HP, Leach H (1979) Vertical microscale distribution of phytoplankton in relation to the thermocline. Mar Ecol Prog Ser 1:187-193

Donaghay PL, Rines HM, Sieburth JMcN (1992) Simultaneous sampling of fine scale biological, chemical, and physical structure in stratified waters. Arch Hydrobiol Beih 36:97-108

Estrada M, Berdalet E (1997) Phytoplankton in a turbulent world. Sci Mar 61:125-140

Fasham MJR (1978) The statistical and mathematical analysis of plankton patchiness. Oceanogr Mar Biol Annu Rev 16: 43-79

Fofonoff P, Millard RC Jr (1983) Algorithms for computation of fundamental properties of seawater. UNESCO Tech Pap Mar Sci 44

Frontier (1987) Applications of fractal theory to ecology. In: Legendre P, Legendre L (eds) Developments in numerical ecology. Springer-Verlag, Berlin, p 335-378

Gibson CH (1980) Fossil temperature, salinity and vorticity turbulence in the ocean. In: Nihoul JCJ (ed) Marine turbulence. Elsevier, Amsterdam, p 221-257

Green T, Diez T (1995) Vertical plankton transport due to selfinduced convection. J Plankton Res 17:1723-1730

Hallegraeff GM, Steffensen DA, Wetherbee R (1988) Three estuarine Australian dinoflagellates that can produce paralytic shellfish toxins. J Plankton Res 10:533-541

Hasle GR (1950) Phototactic vertical migration in marine dinoflagellates. Oikos 2:162-176

Hasting HM, Sugihara G (1993) Fractals: a user's guide for the natural sciences. Oxford University Press, Oxford

Hutchinson GE (1961) The paradox of the plankton. Am Nat 95:137-146

Journel AC, Huijbregts CJ (1978) Mining geostatistics. Academic Press, London

Kamykowski D, Yamasaki H, Yamasaki AK, Kirkpatrick G (1997) A comparison of how different orientation behaviours influence dinoflagellate trajectories and photoresponses in turbulent water columns. In: Anderson DM, Cambella AD, Hallegraeff GM (eds) The physical ecology of harmful algal blooms. Springer-Verlag, Berlin, p 581-599

Karp-Boss L, Boss E, Jumars P (1996) Nutrient fluxes to planktonic osmotrophs in the presence of fluid motion. Oceanogr Mar Biol Annu Rev 34:71-107

Katz J, Donaghay PL, Zang J, King S, Russell K (1999) Submersible holocamera for detection of particle characteristics and motions in the ocean. Deep-Sea Res Part I 46: 1455-1481

Kessler J (1985) Hydrodynamic focussing of motile algal cells. Nature 313:218-220

Kessler J (1986) Individual and collective dynamics of swimming cells. J Fluid Mech 173:191-205 
Kils U (1993) Formation of micropatches by zooplanktondriven microturbulence. Bull Mar Sci 53:160-169

Kiørboe T (1997) Small-scale turbulence, marine snow formation, and planktivorous feeding. Sci Mar 61:141-158

Kirk JTO (1994) Light and photosynthesis in aquatic systems, 2nd edn. Cambridge University Press, Cambridge

Lazier JRN, Mann KH (1989) Turbulence and the diffusive layers around small organisms. Deep-Sea Res 31: 1721-1733

Mackas DL, Denman KL, Abbott MR (1985) Plankton patchiness: biology in the physical vernacular. Bull Mar Sci 37:652-674

MacKenzie BR, Leggett WC (1993) Wind-based models for estimating the dissipation rates of turbulent energy in aquatic environments: empirical comparisons. Mar Ecol Prog Ser 94:207-216

Mandelbrot B (1977) Fractals: form, chance and dimension. Freeman, London

Mandelbrot B (1983) The fractal geometry of nature. Freeman, New York

Mandelbrot B, Wallis JR (1969) Some long-run properties of geophysical records. Water Resour Res 5:321-340

McAlice BJ (1970) Observations on the small-scale distributions of estuarine phytoplankton. Mar Biol 7:100-111

Millero FJ, Chen CT, Bradshaw A, Schleicher K (1980) A new high pressure equation of state for seawater. Deep-Sea Res 27:255-264

Mitchell JG, Fuhrman JA (1989) Centimeter scale vertical heterogeneity in bacteria and chlorophyll a. Mar Ecol Prog Ser 54:141-148

Mitchell JG, Okubo A, Fuhrman JA (1985) Microzones surrounding phytoplankton for the basis for a stratified marine microbial ecosystem. Nature 316:58-59

Mitchell JG, Okubo A, Fuhrman JA (1990) Gyrotaxis as a new mechanism of generating spatial heterogeneity and migration in microplankton. Limnol Oceanogr 35: 123-130

Montagnes DJS, Poulton AJ, Shammon TM (1999) Mesoscale, finescale and microscale distribution of micro- and nanoplankton in the Irish Sea, with emphasis on ciliates and their prey. Mar Biol 134:167-179

Oakey NS, Elliot JA (1982) Dissipation within the surface mixed layer. J Phys Oceanogr 20:604-617

Okubo A (1980) Diffusion and ecological problems: mathematical models. Springer-Verlag, Berlin

Owen RW (1989) Microscale and finescale variations of small plankton in coastal and pelagic environments. J Mar Res 47:197-240

Pahlow M, Riebesell U, Wolf-Gladrow DA (1997) Impact of cell shape and chain formation on nutrient acquisition in marine diatoms. Limnol Oceanogr 42:1660-1672

Editorial responsibility: Otto Kinne (Editor), Oldendorf/Luhe, Germany
Palmer MW (1988) Fractal geometry: a tool for describing patterns of plant communities. Vegetatio 75:91-102

Pedley T, Kessler J (1990) A new continuum model for suspensions of gyrotactic microorganisms. J Fluid Mech 212: $155-182$

Peitgen HO, Jurgens H, Saupe D (1992) Chaos and fractals: new frontiers of science. Springer-Verlag, New York

Platt T (1972) Local phytoplankton abundance and turbulence. Deep-Sea Res 19:183-187

Platt T, Denman KL (1975) Spectral analysis in ecology. Annu Rev Ecol Syst 6:189-210

Rothschild BJ, Osborne TR (1988) Small-scale turbulence and plankton contact rates. J Plankon Res 10:465-474

Russel RW, Hunt GL, Coyle KO, Cooney RT (1992) Foraging in a fractal environment: spatial patterns in a marine predator-prey system. Landscape Ecol 7:195-209

Seuront L, Lagadeuc Y (1997) Characterisation of space-time variability in stratified and mixed coastal waters (Baie des Chaleurs, Quebec, Canada): application of fractal theory. Mar Ecol Prog Ser 159:81-95

Seuront L, Lagadeuc Y (1998) Spatio-temporal structure of tidally mixed coastal waters: variability and heterogeneity. J Plankton Res 20:1387-1401

Seuront L, Schmitt F, Lagadeuc Y, Schertzer D, Lovejoy S (1999) Universal multifractal analysis as a tool to characterize multiscale intermittent patters: example of phytoplankton distribution in turbulent coastal waters. J Plankton Res 21:877-922

Strutton, PG, Mitchell JG, Parslow JS (1996) Nonlinear analysis of chlorophyll a transects as a method of quantifying spatial structure. J Plankton Res 18:1717-1726

Sugihara G, May RM (1990) Applications of fractals in ecology. Trends Ecol Evol 5:79-86

Sundby S (1997) Turbulence and ichthyoplankton-influence on vertical distributions and encounter rates. Sci Mar 61 (Suppl 1):159-176

Tiselius P (1992) Behavior of Acartia tonsa in patchy food environments. Limnol Oceanogr 37:1640-1651

Tiselius P, Nielsen G, Nielsen TG (1994) Microscale patchiness of plankton within a sharp pycnocline. J Plankton Res 16:543-554

Villarino ML, Figueiras FG, Jones KJ, Alvarez-Salgado XA, Richard J, Edwards A (1995) Evidence of in situ diel vertical migration of a red-tide microplankton species in Ria de Vigo (NW Spain). Mar Biol 123:607-617

Vogel S (1994) Life in moving fluids: the physical biology of flow, 2nd edn. Princeton University Press, Princeton

Webb KL, D'Elia CF (1980) Nutrient and oxygen redistributions during a spring neap tidal cycle in a temperate estuary. Science 207:983-985

Zar JH (1984) Biostatistical analysis. Prentice-Hall, London

Submitted: July 4, 2001; Accepted: April 15, 2002

Proofs received from author(s): June 27, 2002 